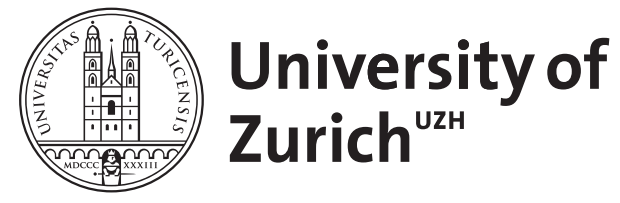

Zurich Open Repository and Archive

University of Zurich

University Library

Strickhofstrasse 39

CH-8057 Zurich

www.zora.uzh.ch

Year: 2007

Childhood cancer - are there predictors of parental well-being?

Bergsträsser, Eva

DOI: https://doi.org/10.1007/s00520-007-0257-4

Posted at the Zurich Open Repository and Archive, University of Zurich

ZORA URL: https://doi.org/10.5167/uzh-156668

Journal Article

Published Version

Originally published at:

Bergsträsser, Eva (2007). Childhood cancer - are there predictors of parental well-being? Supportive Care in Cancer, 15(7):799-800.

DOI: https://doi.org/10.1007/s00520-007-0257-4 


\title{
Childhood cancer-are there predictors of parental well-being?
}

\author{
Eva Bergsträsser
}

Received: 29 March 2007 / Accepted: 4 April 2007 / Published online: 28 April 2007

(C) Springer-Verlag 2007

Childhood cancer is one of the most threatening diagnoses families can be confronted with. As in adulthood, the diagnosis of cancer is directly associated with the idea of suffering and death. Cancer is a metaphor for death that might never be eradicated irrespective of rising survival curves, especially in childhood cancer.

Nevertheless, parents who are confronted with the diagnosis of cancer of their loved child will enter a process of coping. This process has also been called the "unexpected career" [1]. This expression is well deserved, as it acknowledges the tremendous commitment and competence that parents have who care for their child with cancer. However, it is well known that cancer affects the whole family and other systems connected with the patient and the family. This is a particular issue in pediatric oncology where it includes parents and siblings. One answer to this longstanding awareness can be found in the well-established psychosocial support, which has become an integral part of comprehensive cancer care.

In the pediatric oncology literature, many studies have focused the effects of childhood cancer on parents. A multitude of studies has made valuable contributions to parental coping in childhood cancer. The complexity of stress and coping related to childhood cancer emerges through such studies [2, 3]; however, many aspects remain unclear. We still only partially understand the inter-relationships of different factors relevant to the caregiving process. Besides the clinician's open eyes and mind, a better understanding of the caregiving stress and process of coping or even

E. Bergsträsser $(\bowtie)$

Paediatric Oncology, University Children's Hospital,

Steinwiesstrasse 75, 8032 Zurich, Switzerland

e-mail: eva.bergstraesser@kispi.unizh.ch predictors of parental well-being would be a requirement for better care of both patient and family.

In the same context as Lazarus and Folkman [4], one could approach this problem by thinking about the theoretical background of stress and coping. It appears that this was the underlying rationale for the approach chosen by Klassen et al. [5]. Their study, published in this issue, is directed at the wide variation of psychological adjustments of parents caring for a child with cancer. The authors conducted a systematic review of the literature to identify the main factors previously described to explain this variability. A selection of 48 articles was incorporated in a multidimensional caregiving model-the Caregiving Process and Caregiver Burden Model, previously published by Raina et al. [6] from McMaster University Hamilton, Ontario. This theoretical model was originally developed to obtain a more complete picture of caregiving for children with developmental disabilities. Klassen, Raina, and coworkers modified the model to study parental caregivers in a different setting of health problems. In the given context of childhood cancer, six constructs were included as outcome variables: background/context variables, child characteristics, caregiver strain, self-perception, coping factors, and caregiver's physical and psychological health. The results show that poorer caregiver psychological health was associated with child characteristics, such as behavior problems, depression, emotional, or somatic distress. As is commonly experienced in daily clinical practice, time could heal at least some of the wounds (measured as time since diagnosis). In addition, the condition and prognosis of the child played an important role in the well-being of parents. In this context, it is unfortunate that different cancer entities have not been specified. I would speculate that parents of children with brain tumors have poorer outcomes compared to those with children suffering from other solid tumors, 
such as nephroblastoma or non-high-risk leukemia. A more recent study that focused on time since diagnosis and types of cancer evaluated children and adolescents with newly diagnosed cancer. Interestingly, it could be shown that 6 weeks after diagnosis, children with leukemia were the most affected in the majority of dimensions of healthrelated quality of life (HRQL), and 1 year after diagnosis, children with brain tumors seemed to be the most affected [7]. Surprisingly, Klassen et al. found no evidence for the relationship between socioeconomic status and caregiver strain as has been shown by Sloper [3].

Considering time since diagnosis, it may also be interesting to evaluate the long-term outcomes of these families affected by childhood cancer. Symptoms of post-traumatic stress disorder (PTSD) have been reported in former pediatric cancer patients and are even more accentuated in their parents in a frequency of up to $50 \%$ [8-10]. The development of PTSD is comparable to the experience of pain. In pain, the stimulus of pain does not predict the individually perceived pain and outcome of pain, e.g., the development of chronic pain. Similarly, the amount of stress received by a parent in the context of childhood cancer does not necessarily correlate to the mother or father's real suffering or the risk to develop PTSD. Furthermore, timing of traumatic stress does not correlate with the time of development of symptoms of PTSD.

An important question is whether PTSD in survivors and families can be diminished. Kazak et al. [8] have performed a randomized clinical trial of a family intervention [Surviving Cancer Competently Intervention Program (SCCIP)] integrating cognitive-behavioral and family system approaches to aim a reduction of PTSD or posttraumatic stress symptoms (PTSS). One hundred fifty families participated 1 to 12 years after completion of cancer treatment. Families randomized to the treatment group received the intervention 4 to 6 months after baseline data collection, and reevaluation took place 3 to 5 months after intervention. The intervention consisted of a four-session, 1-day program, whereas the control group remained without intervention until the time of reevaluation when intervention was offered to the participants. PTSS scores, especially intrusive thoughts among fathers and arousal among survivors, were decreased in the intervention group, irrespective of time since treatment ended. Interestingly, no significant effects were found for mothers. Thus, it had been concluded that brief interventions focused on specific aspects of medical trauma would be warranted.
As a pediatric oncologist, I wish to formulate a vision. Given the fact that the majority of children with cancer can be cured of their disease, we should further focus to reach the aim of a "truly cured child," as this had been formulated by Jan van Eys in 1977 [11]. As a "truly cured child" is strongly associated to its family, cure includes the family and is meant as a psychosocial cure. To reach this goal given the scarce resources, it will be necessary to consider the true needs for interventions and support in even more sophisticated concepts of psychosocial, family-based pediatric cancer care of the future. The paper of Klassen et al. may become one of the valuable milestones for further research in this field.

\section{References}

1. Aneshensel CS, Pearlin LI, Mullan JT, Zarit SH, Whitlatch CJ (1995) Profiles in caregiving: the unexpected career. Academic, San Diego

2. Van Dongen-Melman JEWM, Van Zuuren FJ, Verhulst FC (2000) Experiences of parents of childhood cancer survivors: a qualitative analysis. Patient Educ Couns 34:185-200

3. Sloper P (2000) Predictors of distress in parents of children with cancer. A prospective study. J Pediatr Psychol 25(2):79-91

4. Lazarus RS, Folkman S (1984) Stress, appraisal, and coping. Springer, New York

5. Klassen A, Raina P, Reineking S, Dix D, Pritchard S, O'Donnell M (2007) Developing a literature base to understand the caregiving experience of parents of children with cancer. A systematic review of factors related to parental health and well-being. Support Care Cancer (in press). DOI 10.1007/s00520-007-0243-x

6. Raina P, O’Donnell M, Schwellnus H, Rosenbaum P, King G, Brehaut J, Russell D, Swinton M, King S, Wong M, Walter SD, Wood E (2004) Caregiving process and caregiver burden: Conceptual models to guide research and practice. BMC Pediatrics $4: 1-13$

7. Landolt MA, Vollrath M, Niggli FK, Gnehm HE, Sennhauser FH (2006) Health-related quality of life in cildren with newly diagnosed cancer: a one year follow-up study. Health Qual Life Outcomes 4:63

8. Kazak AE, Alderfer MA, Streisand R, Simms S, Rourke MT, Barakat LP, Gallagher P, Cnaan A (2004) Treatment of posttraumatic stress symptoms in adolescent survivors of childhood cancer and their families: a randomized clinical trial. J Fam Psychol 18(3):493-504

9. Landolt MA, Boehler U, Schwager C, Schallberger U, Nuessli R (1998) Post-traumatic stress disorder in paediatric patients and their parents: an exploratory study. J Paediatr Child Health 34:539-543

10. Kazak AE (2005) Evidence-based interventions for survivors of childhood cancer and their families. J Pediatr Psychol 30(1):29-39

11. Van Eys J (1985) Caring toward cure. Child Health Care 13 (4):160-166 